\title{
Levi's Challenge and Peirce's Theory/Practice Distinction
}

\author{
KENNETH BOYD
}

\begin{abstract}
Isaac Levi (1980) targets an implicit tension in C.S. Peirce's epistemology, one that exists between the need to always be open-minded and aware of our propensity to make mistakes so that we do not "block the road of inquiry," and the need to treat certain beliefs as infallible and to doubt only in a genuine way so that inquiry can proceed in the first place. Attempts at alleviating this tension have typically involved interpreting Peirce as ascribing different normative standards to different areas of inquiry. I argue here that such "double-standard" interpretations face significant problems. I offer instead an interpretation of Peirce on which the differences between different areas of inquiry are descriptive rather than normative. Such a view resolves Levi's tension while interpreting Peirce as consistently subscribing to one normative standard for all inquiry.
\end{abstract}

Keywords: Charles Peirce, Isaac Levi, Fallibilism, Inquiry.

Isaac Levi (1980) attributes the following collectively inconsistent positions to C.S. Peirce:

1. The corrigibility of human knowledge, i.e. that all and any beliefs we hold are always potentially subject to revision.

2. Categorical fallibilism as an epistemological commitment, i.e. that we can never achieve maximum certainty pertaining to any of our beliefs. As Levi puts it, categorical fallibilism is the position that "at no time should [subject] $X$ discount the falsity of any matter of fact as not a serious possibility. Thus all logical possibilities (i.e., hypotheses consistent with the urcorpus $U K$ ) should be considered serious possibilities by every $X$ and at every time" (14). The "urcorpus" $(U K)$ "consists of all logical truths, set theoretical truths, and mathematical truths expressible in [language] $L "(7)$.

3. Knowledge as the standard for serious possibility: " $X$ 's knowledge at $t$ serves as a standard for distinguishing truth-value-bearing hypotheses whose truth is a serious possibility according to $X$ at $t$ from those whose truth is not a serious possibility according to $X$ at $t^{\prime \prime}$ (3). Levi presents the following example: although it is logically possible that a coin, when tossed, should "fly out towards Alpha Centauri" instead of coming down heads or tails, my knowledge of coins and their behavior rules out this logical possibility as being a serious one (3).

According to Levi, (1) is inconsistent with (2) and (3): since categorical fallibilism dictates that all logical possibilities are serious possibilities, combining this with the view that knowledge is the standard for serious possibility entails that the only knowledge we can have is in the UK. But since the UK contains only logical, set theoretical and mathematical truths, knowledge of any member of the UK is therefore incorrigible. Thus accepting both (2) and (3) forces us to reject (1). Levi's argument targets an implicit tension in Peirce's epistemology, one that exists between the need to always be open-minded and aware of our propensity to make mistakes so that we do 
not "block the road of inquiry," and the need to treat certain beliefs as infallible and to only doubt in a genuine way so that inquiry can proceed in the first place. To evaluate Levi's criticism and to illustrate the tension further, we need first to determine whether Peirce is committed to all of (1)-(3) above (I will address them out of order).

\section{Peirce's Commitment to Corrigibilism}

Peirce's motivations for adhering to corrigibilism are many. For example, early in his career, in "The Fixation of Belief," Peirce considers the method of tenacity, the method of authority, the $a$ priori method, and the method of science as ways in which we might choose to conduct inquiry. All but the last are unable to lead us to truths, for it is the only one that gives us a standard against which to determine if our beliefs are, in fact, true. Although the scientific method will lead us to truth eventually, we cannot ever be certain that any particular conclusion we reach will be true, and we will invariably reach false conclusions as inquiry proceeds. Because the scientific method is prone to error in the short-term, we cannot be absolutely certain about the truth of any of our beliefs, and, in turn, such beliefs must always be treated as fair game for future revision.

We can also see Peirce's commitment to corrigibilism when he describes the relationship between scientific inquiry and so-called "facts":

[Science] feels from that moment [of appealing to empirical confirmation] that its position is only provisional. It must then find confirmations or else shift its footing. Even if it does find confirmations, they are only partial. It still is not standing upon the bedrock of fact. It is walking upon a bog, and can only say, this ground seems to hold for the present. ... Science, when it comes to understand itself, regards facts merely as the vehicle of eternal truth ... (CP 5.589)

What are taken to be facts in scientific inquiry, then, often only provide temporary bases for inquiry: as we must be able to move to different ground in a bog, we must be able to give up our reliance on what we take to be facts. In general, the only way we can reach true conclusions for Peirce is through reasoning, and since reasoning is inherently fallible, any conclusion we reach should be able to be overturned if necessary (CP 1.141).

\section{Peirce's Critical Common-Sensism}

As Peirce's views on the nature of inquiry commit him to (1), his "critical common-sensism" seems to commit him to (3). For Peirce, inquiry proceeds in the following way (what Levi calls the "belief-doubt" model of inquiry): one starts with a set of beliefs which create in him or her certain expectations. He or she then encounters evidence which upsets these expectations: this is "surprising" to the inquirer, who then doubts the challenged beliefs. While in a state of doubt, the inquirer strives to once again settle her beliefs. It is the process of having one's established beliefs challenged and settling upon new beliefs that constitutes the process of inquiry. Thus to inquire at all, we need to have a set of settled beliefs from which to begin: inquiry has to start from somewhere. It would be a mistake, though, to think that because doubt is necessary for inquiry that therefore any possibility for doubt whatsoever can affect the process of inquiry; nor should we think that we should seek out doubt for inquiry's sake. The beliefs that act as the basis for our inquiries are not those reached by some process of Cartesian introspection where we doubt everything possible and see what remains, but are rather those that we hold at the time of setting out to inquire: 
[T] here is but one state of mind from which you can "set out," namely, the very state of mind in which you actually find yourself at the time you do "set out,"-a state in which you are laden with an immense mass of cognition already formed, of which you cannot divest yourself if you would ... (CP 5.416, EP 2:336).

Indeed, Peirce calls Cartesian doubts "paper" or "tin" (in other words, inauthentic): "Do you call it doubting to write down on a piece of paper that you doubt? If so, doubt has nothing to do with any serious business. ... Now, that which you do not at all doubt, you must and do regard as infallible, absolute truth" (Ibid.).

These ideas are reflected in Peirce's "Critical Common-Sensism," which he outlines as having six "characters." Most important for our purposes are the following:

(I) There are propositions and inferences which are indubitable: these are those beliefs that we cannot help but accept. Again, we might choose to question our beliefs as part of an intellectual exercise, but these doubts are inauthentic:

It is important for the reader to satisfy himself that genuine doubt always has an external origin, usually from surprise; and that it is as impossible for a man to create in himself a genuine doubt by such an act of the will as would suffice to imagine the condition of a mathematical theorem, as it would be for him to give himself a genuine surprise by a simple act of the will (CP 5.443, EP 2:348).

(II) The propositions which we generally consider to be indubitable are liable to change over time. Thus the set of beliefs that we cannot help but accept now may be different from those that we will have to accept in the future (Peirce's example is the belief in a Biblical origin story before the advent of the theory of evolution).

(V) The critical common-sensist has "high esteem" for doubt and recognizes that the beliefs he considers indubitable today may be doubted tomorrow. But again, "his hunger is not to be appeased with paper doubts: he must have the heavy and noble metal, or else belief" (CP 5.514). ${ }^{1}$

In these passages we can see how Peirce holds a position akin to (3). ${ }^{2}$ The set of beliefs at the time of the beginning of inquiry are, in Levi's terms, our corpus of beliefs which forms the background against which inquiry proceeds, and the beliefs we consider indubitable determine which possibilities of error are genuine and which are merely paper.

\section{Categorical Fallibilism, and Peirce's Theory/Practice Divide}

The tension in Peirce's position arises if he subscribes to categorical fallibilism: how can any of our beliefs withstand doubt, and in turn be a basis for inquiry, if every logical possibility of error is a legitimate cause for doubt? Obviously, we can relieve the tension by denying that Peirce is a categorical fallibilist. As Levi recognizes, Peirce at some times holds a position similar to (2), while at other times he appears to deny it. These assertions and denials are not at random; rather, Peirce appears to be a categorical fallibilist when discussing inquiry in the realm of "theoretical science" but not when discussing inquiry in the practical realm. This leads Levi to claim that Peirce employs an epistemological double-standard: fallibilism for science and infallibilism for practical inquiry.

Peirce seems to hold the view that the scientific and practical realms are of different kinds and thus inquiry within the respective realms should be conducted differently. For 
instance, in "Philosophy and the Conduct of Life" he states that "pure theoretical knowledge, or science, has nothing directly to say concerning practical matters, and nothing even applicable at all to vital crises" (CP 1.637, EP 2:33). Similarly, in "The First Rule of Logic" he states that "[t]o adhere to a proposition in an absolutely definitive manner ... is something which in practical concerns ... we sometimes cannot and ought not to avoid; but to do so in science amounts simply to not wishing to learn" (EP 2:56). Elizabeth Cooke (2006) notes two reasons why Peirce might think that practical and scientific inquiry are distinct. First, the former is "short-term," concerned with immediate, personal goals, whereas the latter is "long-term," concerned with "the entire human community of inquiry." (67) Second, Peirce appears to hold the view that beliefs are found in the former but not the latter: "practical holding for true ... alone is entitled to the name of Belief, while the other [kind of holding for true] is that acceptance of a proposition which in the intention of pure science remains always provisional" (EP 2:56). It is science's nature as "always provisional" that forbids it from dealing in beliefs, which are, by definition, undoubted. Levi points to an oft-quoted passage that appears to exemplify the difference between practical and scientific inquiry:

If a proposition is to be applied to action, it has to be embraced, or believed without reservation. There is no room for doubt, which can only paralyze action. But the scientific spirit requires a man to be at all times ready to dump his whole cart-load of beliefs, the moment experience is against them. The desire to learn forbids him to be perfectly cocksure that he knows already (CP 1.55).

Inquiring in the practical realm requires us not to doubt our settled beliefs so they can establish a basis from which inquiry can proceed, while scientific inquiry requires precisely this kind of doubt in order to advance.

Demarcating theory and practice will relieve the tension in Levi's inconsistent triad. In the realm of practical inquiry, Peirce is not a categorical fallibilist: in this realm, commonsensism reigns, and the beliefs which we hold to be settled are not subject to genuine doubt in the form of mere logical possibilities (again, the fifth character of critical common-sensism is that our hunger for doubt is not satiated by mere paper). Indeed, Levi argues elsewhere that this is precisely the commitment that we need to reject. In "Induction According to Peirce" he argues:

[I]f knowledge is equated with the standard for serious possibility, Peirce was an epistemic corrigibilist. Because the standard for serious possibility is revisable and, indeed, legitimately so, it cannot be restricted to logical truths on all occasions and, hence, categorical fallibilism must ... be rejected. (90)

Hence, we can relieve Peirce of the charge of inconsistency by arguing that, practically speaking, Peirce holds (1) and (3) but denies (2).

On the other hand, in the realm of scientific inquiry knowledge is not the standard for serious possibility: we should not appeal to a corpus of background knowledge in order to determine which propositions to doubt, as we will have no undoubted, settled beliefs at all. Theoretically speaking, Peirce accepts (1) and (2) but denies (3), again avoiding inconsistency. In other works, Levi presents further reasons why Peirce cannot adhere to (3) in the realm of scientific inquiry. In "Messianic vs. Myopic Realism," for example, Levi argues that Peirce's view of scientific inquiry is faced with the following problem: if the goal of scientific inquiry is the "truth in the End of Days" (being the so-called "messianic" realist position) and inquiry begins from a set of beliefs that we consider to be true, what possible justification could we have 
for giving up those beliefs in the face of recalcitrant evidence? After all, we are already in possession of what we take to be truths, so we have already reached our goal! As Levi puts it:

[A]dvocates of [Peirce's] conception of the aim of inquiry appear committed to the view that if some proposition is recognized to be certainly true, one cannot have good reason for moving to a position of suspense. That is to say, any proposition in the standard for serious possibility and, hence, by the agent's lights infallibly true should also by his lights be incorrigibly true. (622)

The goals of scientific inquiry according to the messianic realist are thus incompatible with the corrigibility of knowledge and a set of undoubted beliefs acting as the basis for inquiry. Again, we can avoid inconsistency by rejecting the view that in the case of scientific inquiry knowledge acts as the standard for serious possibility. ${ }^{3}$

Demarcating theory and practice commits Peirce to two views with which Levi disagrees: first, that knowledge is not in all cases the standard for serious possibility, and second, that there is no single standard of serious possibility for practical and scientific inquiry. I think Levi is correct that the double-standard is undesirable, but for different reasons: positing such a strict distinction between theory and practice has consequences with which Peirce would not agree.

\section{Problems for the Theory/Practice Divide}

Cooke notes two problems for the purported theory/practice split. First, it puts fallibilism in danger of becoming irrelevant. In practical inquiry beliefs have to be considered infallible, since the nature of a belief is that it is not doubted. So fallibilism seems to pertain solely to those positions held in the realm of scientific inquiry. But we have seen that because scientific inquiry needs to be open to all possibilities, it does not actually deal in beliefs; rather, science deals in hypotheses. But it is in the inherent nature of a hypothesis never to have been conceived to be anything like infallible. So what does fallibilism add to our theory? Scientific hypotheses are fallible, but we knew this already: that's why they are hypotheses! In addition to making most of what Peirce says about fallibilism redundant, Cooke argues that a theory/practice distinction will take the "normative bite" out of fallibilism: fallibilism is not meant simply to be an observation about our limitations as inquirers; it also guides us in how we conduct inquiry. However, the normative lessons of fallibilism are vestigial under a theory divided between theory and practice, since it tells us merely not to settle upon positions that are, by definition, unable to be settled upon.

Second, endorsing categorical fallibilism for scientific inquiry seems to commit Peirce to the Cartesian mindset he wants to avoid. Peirce rails against Descartes' process of doubting beliefs that are even conceivably false because such a process is inauthentic (indeed, the doubts that Descartes entertains in his Meditations are often mentioned by Peirce as paradigmatic examples of "paper" doubts). But in the scientific realm categorical fallibilism recommends that the scientist entertain precisely these potentially inauthentic doubts. Surely the scientist considers certain views to be established, so why should she need to question them in the laboratory when she would be required to abolish such doubts for a similar belief in the practical realm? Categorical fallibilism in the scientific realm is thus antithetical to the lessons Peirce draws from his critiques of inauthentic doubting.

An undesirable upshot of separating the scientific and the practical is that Peirce runs the risk of accepting skepticism and dogmatism at the same time: skepticism when it comes to scientific inquiry, dogmatism when it comes to practical inquiry. A traditional strength of 
fallibilism has been its ability to navigate between these two positions, but a theory/practice divide puts Peirce squarely into both camps simultaneously. Thus, while making the difference between scientific and practical inquiry a difference of kind has the benefit of saving Peirce from Levi's charge of inconsistency, it commits him to additional, perhaps more counterintuitive results.

However, denying the split leaves us where we started, i.e. attributing all of (1)-(3) to Peirce. If we are going to interpret Peirce as consistent ${ }^{4}$ in his views of inquiry we need a way of navigating between the proverbial rock and hard place. Below I will survey two attempts at reconciling the realm of the practical and the scientific, one from Cooke and another from Cheryl Misak, and see if they fare any better against Levi's criticism.

\section{Resolving the Tension: Different Characterizations of "Infallibilism"}

Cooke's suggestion is that we interpret Peirce as holding that the line between theory and practice is not absolute. This is not an ad hoc maneuver: there is evidence to suggest that Peirce himself thinks that the line between theory and practice is not as sharp as he sometimes makes it out to be. Perhaps most significant is his claim, discussed above, that the scientific method of inquiry is the only one that can plausibly keep the road of inquiry open and lead us to truths. Cooke also argues that restricting the term "belief" solely to practical inquiry is an overstatement for Peirce:

The scientist working in the here and now must have something like a belief in order to get scientific inquiry going. An hypothesis may be only a guess, but it is not a shot in the dark. ...Observation also assumes a framework from which to interpret new data. And what shall we call the hypothesis and the theoretical assumptions already in place, if not beliefs? Surely scientific beliefs are habits of action, even if only in the laboratory. It seems these should count as at least low-grade beliefs, if the scientist is willing to act on them. (68)

Again, inquiry needs a starting point. If there are no hypotheses that we are willing to commit to, no beliefs in science, then it is difficult to fathom how scientific inquiry is possible. Cooke's suggestion is that Peirce is too hasty in exiling beliefs from science: at least some scientific hypotheses should count as beliefs. If inquiry proceeds in the same way in science and practice, and both are concerned with beliefs, then the difference between the two realms should be considered only as a difference in degree and not in kind.

Misak's interpretation is in agreement with Cooke. Misak notes that Peirce actually seems ambivalent as to whether science is concerned with beliefs: almost at once Peirce claims that the "accepted propositions" of science are "but opinions at most; and the whole list is provisional. The scientific man is not in the least wedded to his conclusions" alongside the claim that there are "established truths" in science, "propositions to which no competent man today demurs" (2004a, 164, quoting CP 1.635, EP 2:33). Misak draws the conclusion that since Peirce seems to be, somewhat confusedly, committed both to the existence and nonexistence of beliefs in science, we should assume a charitable interpretation and attribute to him the view that beliefs do, in fact, belong in science.

If we are to attribute to Peirce the view that there are beliefs in scientific inquiry, this is the wrong place to look: Misak's evidence is taken out of context. The original passage is as follows: 
Some [hypotheses in science], I grant, [the scientist] is in the habit of calling established truths; but that merely means propositions to which no competent man today demurs. It seems probable that any given proposition of that sort will remain for a long time upon the list of propositions to be admitted. Still, it may be refuted tomorrow; and if so, the scientific man will be glad to have got rid of an error. There is thus no proposition at all in science which answers to the conception of belief. (CP 1.635, EP 2:33)

By the end of the passage, Peirce is far from ambivalent as to the place of beliefs in science. Although I think Misak is incorrect in drawing the conclusions she does from this passage, it illustrates well the tension between Peirce's view that scientific inquiry needs to be open to all possibilities and Cooke's argument that requiring the scientist to doubt indiscriminately is antithetical to Peirce's insistence that only genuine doubt can advance inquiry. If there are, in science, "propositions to which no competent man today demurs," how can a "competent man" doubt them in a genuine way?

We might be able to relieve the tension differently. Misak proposes to reconcile fallibilism and critical common-sensism by distinguishing between two different kinds of certainty: "indubitability," which pertains to practical certainty, specifically those beliefs which we do not doubt, and "infallibility," which is an "absolute or abstract" kind of certainty (2004b, 54-5). According to Misak's interpretation, when Peirce says that all of our beliefs are fallible, he is speaking in an absolute sense: there is no possible way that we could attain absolute certainty about the truth of any of our beliefs. This is due to the way Peirce conceives of truth, namely in terms of the beliefs of a hypothetical final community: whatever is believed at the "end of inquiry" is what is true. Misak expresses Peirce's view of truth as a biconditional: "[hypothesis] $\mathrm{H}$ is true, if and only if it would be believed at the end of a prolonged inquiry" (ibid., 42). The right-to-left portion of the biconditional, what Misak calls the "inquiry to truth" or "I-T" direction, tells us why we cannot be certain of the truth of any of our beliefs: "if, if inquiry relevant to $\mathrm{H}$ were pursued as far as it could fruitfully go, $\mathrm{H}$ would be believed, then $\mathrm{H}$ is true" (ibid., 43). ${ }^{5}$ We cannot attain absolute certainty for any of our beliefs because we are simply in no position to know whether the antecedent of this conditional has been satisfied; we can never be certain when we have pursued inquiry into a hypothesis as far as it could go. In Misak's words, "the final opinion does not glow in the dark" (ibid., 53).

That we cannot know when our beliefs are true does not imply that we do not hold true beliefs. On Misak's interpretation our ignorance is second-order: we can have true beliefs, but we cannot know when we have true beliefs. Certainty is defined differently depending on the order: first-order belief claims are evaluated in terms of indubitability, whereas second-order claims are evaluated in terms of absolute certainty. Thus we can reconcile Peirce's overarching claims of fallibilism with practical infallibilism: we are infallible when it comes to our beliefs, since at this level "infallibilism" means that we do not hold any beliefs that are dubitable. While the mere logical possibility of error at the first-order can only instill paper doubts, these doubts are not paper when determining whether we know what we know: at the second-order, infallibilism requires absolute certainty, and thus the mere logical possibility that any of our beliefs could be mistaken instills doubts of a "heavier metal."

This interpretation does not rely on a demarcation between scientific and practical inquiry, but it can still relieve the tension in Levi's argument: Peirce is only a categorical fallibilist about second-order knowledge claims. Analogous to the previous dichotomy between scientific and practical reasoning, at the second-order Peirce accepts (2) but denies (3), and at the first-order denies (2) and accepts (3). Once again the tension in Peirce's position is resolved by 
an appeal to a double-standard: instead of different standards of evaluation for propositions in the practical and scientific realms, Misak's solution gives us different standards of evaluation for first- and second-order beliefs.

Cooke argues that establishing a double-standard for the practical and scientific realms has two undesirable consequences: first, that fallibilism becomes redundant, and second, that Peirce is committed to a skeptical mindset that makes his criticisms of inauthentic doubting hypocritical. Is the present double-standard between first- and second-order beliefs equally susceptible? It does not seem to make fallibilism redundant: instead of simply claiming that only hypotheses are fallible, Misak's interpretation gives fallibilism a meta-theoretical role, telling us that while our beliefs are practically certain, any one of them might still be mistaken.

However, Cooke's second concern remains worrisome. Why should we doubt that we can know that we know any of our practically indubitable beliefs? If doubts which have mere logical possibility as their basis should be ignored at the first order, why should they gain significance at the second order? As we saw above, demarcating theoretical from practical inquiry and assigning different standards to each has the counterintuitive consequence that once one enters a scientific setting, doubts that were previously considered irrelevant suddenly gain relevancy. Here the consequences are similarly counterintuitive: although I am able to know certain things, when I reflect on the state of my knowledge I am unable to know that I know those things, since doubts which are irrelevant at the first order cannot be dismissed at the second order. ${ }^{6}$ We also saw earlier how demarcating theory and practice runs the risk of making Peirce a dogmatist about the practical realm and a skeptic about the theoretical realm. We again face a similar problem: Misak's interpretation risks making Peirce a dogmatist about knowledge claims of the first-order and a skeptic about those of the second-order. This second-order skepticism again prescribes a Cartesian mindset that Peirce wants to avoid: we can never be certain about these beliefs, so we must doubt them, authentically or not. We have not yet bridged the gap between fallibilism and critical common-sensism in a satisfactory way: Misak's interpretation seems simply to shift the blame from one double-standard to another. ${ }^{7}$

\section{Resolving the Tension: Different Points of View}

Cooke takes a different stance. According to her interpretation, Peirce vacillates between two different "points of view" when evaluating inquiry: a "first-person" view from the perspective of the inquirer, and another "as a philosopher ... a kind of third-person, reflective point of view" $(2006,78)$. From the first-person point of view, we do not doubt our beliefs, but from the thirdperson point of view we recognize that our beliefs could be mistaken. As a philosopher, Peirce examines inquiry from a third-person reflective point of view, which is evidenced by his arguments for fallibilism. But he is not always consistent in his method of evaluation. Sometimes he switches between viewpoints and considers inquiry from the inquirer's perspective, hence his arguments for critical common-sensism. According to Cooke, it is this switching back-and-forth between viewpoints that makes Peirce's epistemology seem at times contradictory, but it nevertheless represents an important part of his philosophical process (ibid., 79).

Positing a dual-perspective instead of a double-standard gets us out of Levi's dilemma without facing the potential problems of Levi's and Misak's respective interpretations. On the dual-perspective view, Peirce is a categorical fallibilist, but only from a third-person point of view. Once again, as in the double-standards interpretations, in some sense Peirce accepts (2) as a categorical fallibilist, and in another he rejects (2) and accepts (3) as an infallibilist. Unlike a double-standards view, on this reading Peirce is not dogmatic about some areas of inquiry and 
skeptical about others simultaneously; rather, he is always an infallibilist from a certain point of view and always a fallibilist from another. Presumably, one cannot assume both the first- and third-person viewpoints at the same time, and thus Peirce does not run the risk of inconsistency. According to a dual-perspective interpretation, the flaw with Levi's argument is that the three positions he attributes to Peirce conflate different points of view.

The motivation for positing these different points of view pertains to what Cooke takes to be the most important underlying principle of Peirce's philosophy: do not block the road of inquiry. This principle applies in both the scientific and the practical realms and thus provides a link between them. Both points of view are necessary because, according to Cooke, "the key to Peirce's pragmatic inquirer is knowing when to doubt and when to believe, and this may sometimes mean knowing when to take the third-person point of view and when to take the inquirer's, first-person point of view" (ibid., 80). Sometimes in order to advance inquiry, we need to remain steadfast about our beliefs and consider them infallible; other times we need to recognize our propensity to make mistakes and our inability to know when the propositions we believe are true. "What becomes of central importance then is the inquirer's ability to know when to doubt" (ibid.), as sometimes doubts of the kind entertained by the categorical fallibilist will advance inquiry, and sometimes they will block it.

If this is the advice Peirce gives us, it is difficult to see how we could follow it. It relies upon two contentious claims: first, that we can choose when to doubt, and second, that we are able to know when to doubt and when to refrain from doubting. We have seen that genuine doubt is that which "comes from without," usually in the form of surprising recalcitrant experience. Doubting for the sake of doubting is inauthentic, so in what sense do we ever choose when to doubt? Cooke claims that "[b]eliefs (and doubts) are not strictly causal, otherwise Peirce would not have all this advice (conflicting though it is) for the inquirer-believer" (ibid.). If this is the case, then Peirce needs to allow for the possibility of authentic doubting that is not a reaction to recalcitrant experience. But now we are lacking criteria for the authenticity of doubting: what makes certain doubts paper and others metal? Cooke claims that authentic doubting is that which leaves open the road for inquiry. Remember that Peirce believes that as inquiry proceeds, it gets closer to the truth: false beliefs get weeded out as inquiry progresses, eventually reaching the hypothetical end where all investigation has been completed. But as I discuss above, Misak is correct that we cannot be certain when real progress in inquiry has been made or which beliefs that we hold today will get replaced tomorrow. So if we should doubt only when doubting will allow inquiry to advance, but we cannot know when inquiry is advanced, then we are attributing to Peirce an "ought" that does not entail a "can." This is not good advice.

The problem with Cooke's dual-perspective view is that the employment of different perspectives in evaluations of inquiry seems either unprincipled or impossible to uphold as a normative guide. Cooke's strategy is attractive in that it does not posit two distinct realms of inquiry that are subject to different criteria of evaluation, but it ultimately places too much emphasis on fallibilism's normative role. Scientific inquiry differs from practical inquiry not because science should be conducted differently than practical inquiry, but, because of its subject matter and the nature of beliefs, it is conducted differently. Interpreting Peirce in this manner requires us to conceive of categorical fallibilism differently and, as a result, frees him from Levi's charges of inconsistency. This requires looking in more detail at what counts as scientific inquiry, and also at Peirce's views on belief-forming processes.

\section{Pragmatic Categorical Fallibilism}


Peirce's supposed demarcation between practical and scientific inquiry is shocking because it seems blatantly false: to claim that beliefs have no place in science and that science is wholly divorced from practical matters seems wrong-headed. Levi suggests that we can form a more palatable interpretation of Peirce by understanding him to be claiming that belief does not belong in science because the way that science should be conducted is such that we should take into consideration all logical possibilities for error, including ones that the practical inquirer can safely ignore. But even this seems incorrect: as Cooke and Misak have noted, there are obviously certain facts that the scientist takes for granted when conducting inquiry, and thus there appears to be not only a possible place for beliefs in science but a necessary one. Levi's interpretation makes Peirce simply confused about how scientific inquiry occurs.

While Peirce at times speaks as if all inquiry is a kind of scientific inquiry, when he discusses science directly it turns out to be much more narrowly focused. In "The Scientific Attitude" he states that science "does not consist so much in knowing, nor even in 'organized knowledge,' as it does in diligent inquiry into truth for truth's sake, without any sort of axe to grind, nor for the sake of the delight of contemplating it, but from an impulse to penetrate into the reason of things" (CP 1.44). Inquiry that is concerned with anything other than the unimpeded search for truth does not count as science: "if a man occupies himself with investigating the truth of some question for some ulterior purpose, such as to make money, or to amend his life, or to benefit his fellows, he may be ever so much better than a scientific man ... but he is not a scientific man" (CP 1.45). Already we can see how Peirce's conception of the "scientific man" differs considerably from our own. ${ }^{9}$ For Peirce, the mathematician is the best example of a scientist, and even then only when "mathematics is ... busied about purely hypothetical questions" (CP 1.45).

The upshot is twofold: first, even if Peirce is seen as drawing a distinct dividing line between scientific and practical inquiry, the amount of inquiry that legitimately belongs to the former category is small when compared with the latter. Thus we avoid the "wrong-headedness" intuition that once we enter the laboratory we should suddenly start seriously entertaining metaphysical doubts about our beliefs: inquiry pertaining in any way to practical matters is not scientific. Second, Peirce is not advising us to perform scientific inquiry in any particular way; he is rather describing what scientific inquiry consists in. It is this descriptive project that requires him to ban beliefs from science and that can reconcile his overall fallibilism with his supposed infallibilism at the practical level.

Let's look in more detail at how Peirce conceives of a belief. In "How to Make Our Ideas Clear" he states that a belief has three properties: "First, it is something that we are aware of; second, it appeases the irritation of doubt; and, third, it involves the establishment in our nature of a rule of action, or, say for short, a habit" (CP 5.397, W 3:263). The last property is most important, for Peirce further claims that "the essence of belief is the establishment of a habit" and that if two beliefs do not differ in the "modes of action to which they give rise" then they are, in fact, the same belief: "no mere differences in the manner of consciousness of them can make them different beliefs, any more than playing a tune in different keys is playing different tunes" (CP 5.398, W 3:263-264).

It is belief qua habit-inducer that requires Peirce to argue for indubitable beliefs in the realm of practical inquiry but not in the realm of scientific inquiry. When reasoning about practical matters, Peirce recognizes that there are certain logical possibilities that we are not able to rule out as possibilities. He also recognizes that we cannot consider these possibilities in an authentic way. What this amounts to is the following: even if we were to take into active 
consideration the logical possibility that a belief we hold is mistaken, it would not establish in us a different rule of action. The purported infallibilism about practical matters that Peirce endorses relies upon his pragmatic definition of beliefs: if I cannot bring myself authentically to doubt the truth of my beliefs, any inauthentic doubting is not going to change how I act. Remember that inquiry proceeds from beliefs via recalcitrant experience to doubt, through the resolution of that doubt to a new belief. Since beliefs are distinguished by way of the habits they instill, categorical fallibilism at the level of practical beliefs does not advance inquiry simply because it creates no new habits, and in turn no new beliefs. This is not a claim about how we should inquire in the practical realm. Rather it is a descriptive claim about how practical inquiry proceeds.

As shown above, Peirce defines science, at least at some point in his career, as being wholly divorced from practical matters. As a result, it cannot establish rules of action: the minute scientific inquiry tells us how we should act we are outside of the jurisdiction of science. What some have interpreted as a normative claim about how science should proceed, namely by requiring the scientist to be more open-minded and aware of fallibility than the practical inquirer, I interpret here as another descriptive claim: science is, by definition, not concerned with action or the establishment of habits, and thus there are no beliefs in science. Peirce does not recommend that we be fallibilists in the scientific realm and infallibilists in the practical realm. On his view, we should always be fallibilists. But he also thinks that certain possibilities for error are impotent when inquiring into practical matters and potent when inquiring into scientific matters.

One might object that to claim that science is not concerned with the establishment of habits is to once again tread dangerously close to blatant falsehood. Surely there exist scientific habits, viz. technical abilities gained through practice, the expectation of certain established results in experiments, social practices like participating in the process of peer review, etc. ${ }^{10}$ Thus it seems that I am attributing another confused view of science to Peirce. There are a few ways we could handle such an objection. First, we could simply ascribe to Peirce the counterintuitive view that there are no habits in science; after all, we have seen that his views about science often depart from our own. Second, we could argue that while there are scientific habits, they are not the kind of habits that produce beliefs. That habit is the essence of belief implies only that habits are necessary for beliefs, not that they are sufficient. What constitutes a habit for Peirce is manifold, and it is clear that not every instance of a habit is also a belief (Peirce describes laws of nature, for example, as habits). Thus we can answer our objector by arguing that if there are habits in science, then they are not ones that pertain to practical action, and thus they cannot result in beliefs. This answer fits with the way I have interpreted Peirce's view of science thus far: since inquiry that pertains to practical aspects of life is not scientific, scientific habits, if they exist, cannot be ones that have practical effects.

One of Cooke's complaints about demarcating practical and scientific inquiry was that we risk losing some of the "normative bite" of fallibilism; here, I seem to have rendered fallibilism normatively toothless. But Peirce's fallibilism can still guide our actions. Because we cannot establish new beliefs through the entertainment of mere logical possibilities, we should ignore them, but in a practical sense. By entertaining logical possibilities for error in practical inquiry, we are not violating any epistemic rules; we are simply wasting our time. ${ }^{11}$

One might think that we are in fact violating an epistemic rule if we entertain paperquality doubts in our practical inquiry, namely the rule to not block the road of inquiry (the most important rule of all!). After all, since such doubts are not ones that the inquirer takes seriously, considering them will only create self-induced obstacles along inquiry's path. But by considering 
paper doubts we are not blocking the road of inquiry. Rather, we are simply not progressing along it. Cooke notes that Peirce states four ways in which we can block inquiry: "(1) Asserting a claim with absolute certainty; (2) claiming something to be unknowable; (3) holding an element of science to be 'basic, ultimate and independent of aught else'; and (4) holding a claim to be the final and perfect formulation" (30, quoting CP 1.139, EP 2:49). Considering paper doubts in practical inquiry is not at fault in any of the above ways. Peirce's maxim is not meant to tell us that we should always be trying to move inquiry forward; to reiterate Misak's observation, the end of inquiry does not "glow in the dark," since we cannot ever know for certain when inquiry has progressed, nor which beliefs we should question in order to get closer to the truth. Rather, Peirce tells us that we should avoid the dogmatism and hubris that is entailed by claims to absolute certainty.

Reading Peirce as demarcating theory and practice descriptively rather than normatively removes the need to attribute multiple perspectives of evaluation. This view was driven by an interpretation of Peirce that advocates an epistemic norm requiring us to progress inquiry, and thus requires the specification of when a first-person or third-person perspective is necessary. I have noted that this normative requirement conflicts with Misak's observations about truth in terms of the end of inquiry. But it also conflicts with Peirce's view that the "method of science" (now seen to be something of a misnomer since it is applicable to much more than just "science" in Peirce's narrow sense) is the singular method that we must employ if inquiry is to proceed. Peirce does not claim that we should consider inquiry from one point of view in certain instances and another point of view in others. Again, even Peirce's insistence on the method of science is not a normative claim. It is not that we should use the method of science as opposed to other possible methods; it is that the other possible methods are unable to move inquiry forward. Tension arises if we interpret Peirce as claiming that there are different normative standards for different areas of inquiry but not if there are simply descriptive differences between them.

Peirce can consistently hold all of Levi's claims (1) - (3) simultaneously. Human knowledge is still inherently corrigible, so (1) remains true. As for (2), remember that Levi's definition of categorical fallibilism was that "at no time should [subject] $X$ discount the falsity of any matter of fact as not a serious possibility." What's important here is how we interpret the "should" in this definition: Levi intends it to be an epistemic "should," i.e. he holds that ignoring a possibility for error violates an epistemic norm. On the reading of categorical fallibilism where "should" is taken epistemically, failing to take into account the possibility of the falsity of one's belief is bad epistemic practice. Call such a view epistemic categorical fallibilism. But Peirce's view is not that we should ignore logical possibilities in practical inquiry because only a certain class of possibility is salient in a way that affects whether we have knowledge; rather, it is that we should ignore logical possibilities in practical inquiry because considering mere logical possibilities will make no difference in how we act. Taking into account logical possibilities of error with regard to practical matters will not advance inquiry; nevertheless, doing so does not violate an epistemic norm. I have argued that the maxim "do not block the road of inquiry" should be read only as a negative requirement (i.e. it tells us solely what not to do), since a positive requirement to advance inquiry is incompatible with our inability to know when inquiry is actually advanced. Thus Peirce can accept (2) when "should" is given an epistemic reading, but he rejects it when "should" is interpreted in a practical sense; his view is that entertaining paper doubts will not change our habits, so it is a pointless exercise. Call such a view pragmatic categorical fallibilism. 
It is the conflation of epistemic and pragmatic categorical fallibilism under the single heading of "categorical fallibilism" that I think leads Levi to posit that Peirce must be employing a double-standard in his evaluations of inquiry. Although Peirce might seem to be advocating categorical fallibilism in the scientific realm and denying it in the practical, he is, in actuality, accepting epistemic and rejecting pragmatic categorical fallibilism for both realms of inquiry. Thus the standards for both realms of inquiry are the same: mere logical possibility of error is just as unable to cause doubt that can establish new beliefs in science as in practice, since science does not deal in beliefs. Peirce's apparent simultaneous acceptance and rejection of (2) is not dependent upon the subject matter of inquiry, but rather upon different ways in which the normative requirement of categorical fallibilism is cashed out. Peirce accepts categorical fallibilism for both scientific and practical inquiry when the "should" of categorical fallibilism is epistemic, but he rejects it for both kinds of inquiry when the "should" is pragmatic.

Peirce is also committed to (3): knowledge remains the standard for serious possibility, or, in more Peircean terms, the beliefs with which we begin inquiry act as the basis against which we experience recalcitrant evidence, surprise, doubt, and the establishment of a new belief. But (1) is consistent with (2) and (3): we can still consider every logical possibility for error without undermining the beliefs that we use as a basis for inquiry, since mere logical possibility will not result in doubt that can change our habits. The pragmatic nature of beliefs immunizes them from the epistemic challenge of Levi's categorical fallibilism.

The tension that Levi's criticism of Peirce brought out was one existing between the purported necessity of infallibilism as regards practical inquiry and categorical fallibilism as regards scientific inquiry. My attempt to unify these realms of inquiry has been to conceive of Peirce's demarcation of science and practice as a predominantly descriptive rather than normative project: it is not that practical inquiry should be conducted differently than scientific inquiry, it is that the nature of the respective subject matters makes certain doubts effective in one realm and ineffective in another. Likewise, it is not that science should not be concerned with beliefs, it is that it cannot be so concerned, by definition. Peirce does not require us to be fallibilists sometimes and infallibilists at other times. Peirce is always a fallibilist. ${ }^{12}$

University of Toronto

kenneth.boyd@utoronto.ca

\section{REFERENCES}

Cooke, Elizabeth. Peirce's Pragmatic Theory of Inquiry: Fallibilism and Indeterminacy. New York: Continuum, 2006.

Levi, Isaac. The Enterprise of Knowledge: An Essay on Knowledge, Credal Probability, and Chance. Cambridge, MA: MIT Press, 1980.

---. "Messianic vs. Myopic Realism." PSA 1984: Proceedings of the 1984 Biennial Meeting of the Philosophy of Science Association, Vol. 2. Ed. Peter D. Asquith and Philip Kitcher. East Lansing, MI: Philosophy of Science Association, 1985. 617-636.

---. "Induction According to Peirce." Peirce and Contemporary Thought. Ed. Kenneth Laine Ketner. New York: Fordham University Press, 1995. 59-93.

---. "Replies." Knowledge and Inquiry: Essays on the Pragmatism of Isaac Levi. Ed. Erik J. Olsson. Cambridge: Cambridge University Press, 2006. 327-380.

Misak, Cheryl. "C. S. Peirce on Vital Matters." The Cambridge Companion to Peirce. Ed. Cheryl Misak. Cambridge: Cambridge University Press, 2004a. 150-174. 
---, Truth and the End of Inquiry: A Peircean Account of Truth. Expanded paperback edition. Oxford: Oxford University Press, 2004b.

---. "Isaac Levi and His Pragmatist Lineage." Knowledge and Inquiry: Essays on the Pragmatism of Isaac Levi. Ed. Erik J. Olsson. Cambridge: Cambridge University Press, 2006. 18-31.

Peirce, Charles S. Collected Papers of Charles S. Peirce. 8 vols. Ed. C. Hartshorne and P. Weiss (vols.1-6), and A. Burks (vols.7-8). Cambridge, MA: Harvard University Press, 1931-58. References cite volume and paragraph numbers (e.g., CP 5.589).

---. The Writings of Charles S. Peirce. 7 vols. to date. Ed. the Peirce Edition Project. Bloomington, IN: Indiana University Press, 1982-. Cited as W.

---. The Essential Peirce: Selected Philosophical Writings. 2 vols. Ed. Nathan Houser and Christian Kloesel (vol.1) and the Peirce Edition Project (vol.2). Bloomington, IN: Indiana University Press, 1992-1998. Cited as EP.

\section{NOTES}

${ }^{1}$ Also of interest is (VI): propositions are not accepted as indubitable simply because they have not been scrutinized. Thus Peirce avoids the potential objection that what can qualify as indubitable beliefs are not just those that we cannot doubt but also those that we simply have not taken the time to doubt: "Neither the philosophy of Common-Sense nor the man who holds it accepts any belief on the ground that it has not been criticized. For, as already said, such beliefs are not 'accepted."' (CP 5.523)

${ }^{2}$ I hedge by saying "akin" to (3) because it is unclear if Peirce would employ the term "knowledge" in exactly this way. Nothing of importance hinges, I think, on the terminological ambiguity.

${ }^{3}$ In later works, Levi is in general less inclined to focus on Peirce's categorical fallibilism, choosing instead to focus on the implications of his alleged messianic realism, and as a result, presents the option of resolving the inconsistency examined here by rejecting (1). For instance, Levi (2006) argues that accepting messianic realism "either requires abandoning corrigibilism of the present doctrine in favor of categorical fallibilism or abandoning the thesis that $X$ 's state of full belief or knowledge is X's standard of serious possibility" (337). Thus, at least in his more recent writings, Levi seems to endorse rejecting (1) (and, in turn, accepting (2)) as a possible way out of the inconsistency present in accepting messianic realism, (1) and (3) simultaneously. Levi's shift in focus does not, I think, complicate the discussion at hand: since messianic realism can imply the need for categorical fallibilism, the tension in (1)-(3) is present regardless of whether we frame the discussion in terms of the one rather than the other. We could, of course, avoid this particular complaint of Levi's by challenging the view that Peirce is, in fact, a messianic realist; indeed, I think that the right way to interpret Peirce is as having rejected messianic realism. It would take us too far afield to do a thorough job of challenging this view (see Misak (2006), however, for an example of a thorough challenge). Some of the discussion below, however, will give us at least some reason to rethink attributing a messianic realist position to Peirce (n.b. notes 8 and 11).

${ }^{4}$ One might simply think that Peirce was inconsistent in his views, or that he changed his mind over the course of his career (it was, after all, a long career). Cooke $(2006,79)$ argues that there 
is good reason to think that Peirce did not simply change his mind, and I will argue here that it does not require any fancy manoeuvring to reconcile Peirce's view of theory and practice, and thus that the charitable interpretation is the best one.

${ }^{5}$ Misak does not take the I-T conditional as simply a given, although I will treat it as such here. See (2004b) for her argument.

${ }^{6}$ It is a counterintuitive consequence of this position that I should be able to know, for example, where I was born, without being able also to know that I know where I was born.

${ }^{7}$ It seems likely that any strategy that attributes a double-standard is going to run into similar problems, where one realm of inquiry is infallible and dogmatic, and another fallible and skeptical. It is the charge of skepticism that is particularly problematic: for Peirce we cannot authentically be skeptics, so if we attribute to him a skeptical position we must also attribute to him a hypocritical position in regards to the authenticity of doubting.

${ }^{8}$ That this is not good advice is, I think, also reason to question Levi's interpretation of Peirce as a messianic realist. Although scientific inquiry may be such that it tends towards truth at the theoretical end of inquiry, because we are never in a position to know exactly when our beliefs are true the scientist cannot conduct inquiry with this goal explicitly in mind (again, see Misak (2006) for an alternative to Levi's view). It would be similarly bad advice, then, to say that just because we hold certain beliefs to be true now, these undoubted beliefs could not at any point be justifiably overturned.

${ }_{9}^{9}$ For example, Peirce does not consider "chemists who occupy themselves exclusively with the study of dyestuffs" (CP 1.45) as scientists because their research is directed towards a practical end.

${ }^{10}$ Thanks to an anonymous referee for drawing this objection to my attention, and for pointing me at what I take to be the most plausible solution.

${ }^{11}$ I think the discussion here presents a coherent way to understand Peirce's rejection of the role of beliefs in the realm of scientific inquiry without attributing to him the messianic realist position. Again, the messianic realist argues that we cannot inquire on the basis of a set of information that the inquirer takes to be true, because then there would never be a justifiable reason to reject any of those beliefs. I think that this interpretation again requires attributing to Peirce a normative role for fallibilism in scientific inquiry that conflicts with his theory of truth and his view on the nature of belief.

${ }^{12}$ Many thanks to Diana Heney, Robert Lane, and three anonymous referees for their many helpful comments on this paper. 